\title{
Continuous ambulatory peritoneal dialysis and renal transplantation: a five year experience
}

\author{
P K DONNELLY, T W J LENNARD, G PROUD, R M R TAYLOR, R HENDERSON, \\ K FLETCHER, W ELLIOTT, M K WARD, R WILKINSON
}

\begin{abstract}
Continuous ambulatory peritoneal dialysis is a new and increasingly popular method of routine dialysis, but its effect on renal transplantation is uncertain. A nonrandomised comparison was made of the outcome of grafting in patients who had been treated before transplantation with continuous ambulatory peritoneal dialysis with that in patients treated with haemodialysis.

During the five years, 1979-84, after continuous ambulatory peritoneal dialysis was introduced to Newcastle upon Tyne 220 patients have received transplants after either continuous ambulatory peritoneal dialysis (61 patients) or haemodialysis (159 patients). During follow up no significant differences occurred in survival of patients or grafts between the two treatment groups. One year after transplantation the percentages of survivors who had received continuous ambulatory peritoneal dialysis and haemodialysis were $88 \%$ and $91 \%$ respectively, and overall graft survival was $66 \%$ and $72 \%$, respectively. A multiple regression model was used to allow for differences among patients-for example, duration of dialysis and number of preoperative transfusions-on the survival of grafts. When only first cadaver grafts were considered (in 152 patients) graft survival
\end{abstract}

Department of Surgery, Medical School, University of Newcastle upon Tyne, Newcastle upon Tyne NE2 4HH

P K DONNELLY, FRCS, first assistant in transplantation

$T$ W J LENNARD, FRCS, lecturer in surgical sciences

G PROUD, FRCS, consultant surgeon and senior lecturer

R M R TAYLOR, FRCS, consultant surgeon

Department of Statistics, Medical School, University of Newcastle upon Tyne

R HENDERSON, PHD, lecturer in statistics

Department of Medicine, Medical School, University of Newcastle upon Tyne

K FLETCHER, HND, research associate in computer studies

W ELLIOTT, FRCP, consultant physician

M K WARD, FRCP, consultant physician and senior lecturer

$\mathrm{R}$ WILKINSON, FRCP, reader in medicine

Correspondence to: $\mathrm{Mr}$ Donnelly. (non-immunological failures excluded) was not significantly different between the patients treated with continuous ambulatory peritoneal dialysis and haemodialysis.

Continuous ambulatory peritoneal dialysis is not a risk factor in renal transplantation, and its continued use in treatment of potential renal graft recipients is recommended.

\section{Introduction}

Since its introduction in 1946 haemodialysis has been the mainstay of medical management of end stage renal failure. ${ }^{1}$ Unfortunately, for some patients, particularly the elderly and young, haemodialysis is unsuitable. Continuous ambulatory peritoneal dialysis was proposed as a method of treating these difficult patients, ${ }^{2}$ but since its introduction in the United Kingdom in 1978 its application has extended dramatically. ${ }^{3}$

Continuous ambulatory peritoneal dialysis allows a more sustained control of uraemia and a greater reduction in requirements for transfusions than haemodialysis. ${ }^{2}$ As uraemic immunodepression and preoperative blood transfusions contribute to the success of grafting ${ }^{4}{ }^{5}$ patients receiving continuous ambulatory peritoneal dialysis may, theoretically, be at increased risk of graft failure after transplantation. ${ }^{6}$ If this proved correct it would constitute a major disadvantage for patients treated with continuous ambulatory peritoneal dialysis.

As in Newcastle upon Tyne a large proportion of our patients are treated with continuous ambulatory peritoneal dialysis while awaiting transplantation, we were able to test whether this risk is a real one by comparing results of renal transplantation in patients treated with conventional haemodialysis with those treated with continuous ambulatory peritoneal dialysis.

\section{Patients and methods}

Continuous ambulatory peritoneal dialysis was introduced in Newcastle upon Tyne in the treatment of end stage renal failure in December 1978. Before 1979 haemodialysis was the only form of maintenance dialysis available, and patients were treated nonselectively by this technique. After 1979 patients were increasingly 
offered continuous ambulatory peritoneal dialysis as the first line method of dialysis. During the next five years the proportion of patients treated with continuous ambulatory peritoneal dialysis receiving transplants increased from $9 \%$ in 1979 to $43 \%$ in 1983 Patients were considered unsuitable for continuous ambulatory peritoneal dialysis if they had had major lower abdominal operations, known inflammatory bowel disease, and physical or mental inability to cope with the technique, or if they expressed a preference against receiving it. Patients unsuitable for continuous ambulatory peritoneal dialysis were treated with haemodialysis. Between May 1979, when the first patient treated with continuous ambulatory peritoneal dialysis from this centre received a transplant, and 31 December 1983, 231 renal graft allografts were performed.

All patients had previously received transfusions as part of an elective blood transfusion policy. In all but four patients postoperative immunosuppression treatment consisted of azathioprine and prednisolone with pulses of methylprednisolone for episodes of rejection.? The four remaining patients were treated with cyclosporin A. HLA antigens were identified with standard serum samples, ${ }^{8}$ and all recipients' serum samples were not cytotoxic when cross matched with donor lymphocytes. All catheters used for continuous ambulatory peritoneal dialysis were of the Tenckhoff type ${ }^{9}$ and inserted by a standard technique ${ }^{10}$ with routine management, as described previously. ${ }^{11}$ Patients treated with continuous ambulatory peritoneal dialysis were not offered a renal transplant within three weeks of starting a course of antibiotics for diagnosed peritonitis.

Of the 231 renal transplants, 175 were first, 27 second, and five third cadaver grafts. Twenty four patients received kidneys from living related donors, and 15 patients received second grafts during the period of study. At transplantation 11 patients were not receiving dialysis, 159 were receiving regular haemodialysis, and 61 were receiving continuous ambulatory peritoneal dialysis. One patient who was not receiving dialysis, four receiving haemodialysis, and four receiving continuous ambulatory peritoneal dialysis had insulin dependent diabetes mellitus.

A non-randomised comparison of graft survival in patients given continuous ambulatory peritoneal dialysis and haemodialysis was made after a minimum of six months of follow up. Loss of graft was defined as the date of return to maintenance dialysis and the cause of its loss confirmed by histological examination. Patients who died with a functioning graft were regarded as lost to follow up at the time of death. Patients whose grafts failed as a result of rejection were defined as immunological failures whereas grafts failing for technical reasons-for example, urinary leak-were designated as non-immunological failures.

Statistical comparison of patient groups was by $\chi^{2}$ test, Student's $t$ test, or Mann-Whitney U test where appropriate. Survival of patients and grafts was compared by actuarial analysis. ${ }^{12}$ Comparison of risk factors in relation to graft survival was achieved by the Cox proportional hazards model, ${ }^{13}$ a method well accepted in the evaluation of multivariate risk factors in patients receiving transplants. ${ }^{14}$

\section{Results}

\section{SURVIVAL OF PATIENTS AND GRAFTS}

Eleven patients who were not receiving dialysis at transplantation were excluded from the analysis. Of the 220 renal transplants, 53 grafts were lost to follow up as a result of rejection and 22 were non-immunological failures, and 15 patients died with a functioning graft.

Survival of patients was based on analysis of 205 cases as 15 patients received second grafts during the study period. Twenty five patients died after transplantation. There was no significant difference in the proportion of deaths after transplantation among patients treated with continuous ambulatory peritoneal dialysis (7 (12\%) of 61) compared with those treated with haemodialysis (18 (11\%) of 159). Actuarial analysis of survival of patients also confirmed that there was no difference in mortality between the two groups regardless of the interval after transplantation.

Eight $(13 \%)$ out of 61 grafts were non-immunological failures in transplant recipients from the continuous ambulatory peritoneal dialysis group compared with $14(9 \%)$ out of 159 in patients who had received haemodialysis, a difference that was not significant by $\chi^{2}$ analysis. Actuarial analysis of loss of graft from all causes (fig 1) showed no significant difference at any time for those treated with continuous ambulatory peritoneal dialysis or haemodialysis.

Table I compares details of patients' background. No significant differences were found in age, sex ratio, or HLA-A or HLA-B antigen

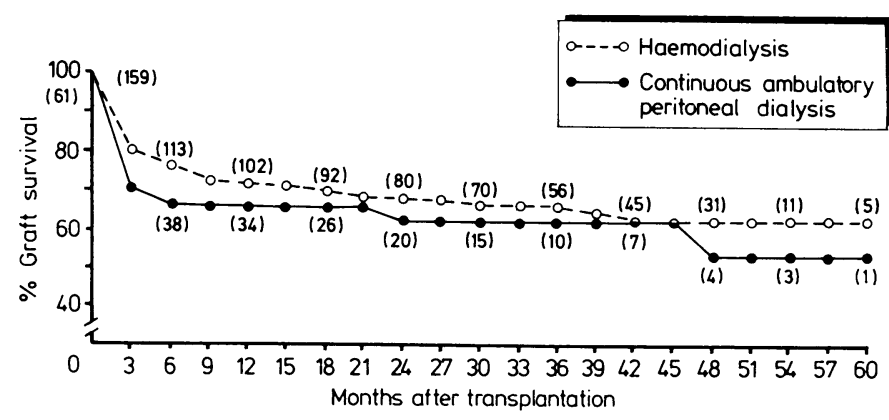

FIG 1 -Renal allograft survival in patients treated with continuous ambulatory peritoneal dialysis and haemodialysis (failures included). Values in parentheses are numbers of functioning grafts at each time point.

ambulatory peritoneal dialysis before transplantation

\begin{tabular}{|c|c|c|c|}
\hline & \multicolumn{2}{|c|}{ Treatment } & \multirow[b]{2}{*}{ p Value } \\
\hline & $\begin{array}{l}\text { Haemodialysis } \\
\quad(\mathbf{n}=159)\end{array}$ & $\begin{array}{l}\text { Continuous } \\
\text { ambulatory } \\
\text { peritoneal } \\
\text { dialysis } \\
(\mathrm{n}=61)\end{array}$ & \\
\hline \multirow{8}{*}{$\begin{array}{l}\text { Mean (SD) age (years) } \\
\text { (range) } \\
\text { Men:women } \\
\text { Mean (SD) matches: } \\
\text { HLA-A } \\
\text { HLA-B } \\
\text { HLA-DR } \\
\text { Median (range) preoperative } \\
\text { transfusions (units) } \\
\text { Median (range) duration of dialysis } \\
\text { (days) }\end{array}$} & $37.9(12 \cdot 6)$ & $38 \cdot 1(7 \cdot 8)$ & NS \\
\hline & $108: 51$ & $38: 23$ & NS \\
\hline & & & NS \\
\hline & $1.53(0.63)$ & $\begin{array}{l}0.59(0.07) \\
1.56(0.62)\end{array}$ & NS \\
\hline & $0.59(0.63)$ & $0.91(0.62)$ & $<0.001$ \\
\hline & & & $<0.0001$ \\
\hline & $7(1-80)$ & $4(1-23)$ & 0.0001 \\
\hline & $860(36-4740)$ & $373(44-3113)$ & $<0.0001$ \\
\hline
\end{tabular}

matches for the two groups of patients. Patients who received haemodialysis received dialysis for significantly longer and had more transfusions before transplantation than those who received continuous ambulatory peritoneal dialysis. There were more donor-recipient HLA-DR matches among the continuous ambulatory peritoneal dialysis group.

\section{GRAFT REJECTION IN FIRST CADAVER RECIPIENTS}

To examine more closely the possible influence of continuous ambulatory peritoneal dialysis on renal allograft rejection, only first cadaver recipients were studied. After exclusion of grafts lost as a result of non-immunological reasons and four patients who were treated with cyclosporin there were 152 patients, 107 of whom had received haemodialysis and 45 continuous ambulatory peritoneal dialysis before transplantation and who were treated by the same postoperative regimen of azathioprine and prednisolone. Actuarial analysis showed no significant effect of type of dialysis on loss of renal allografts from rejection (fig 2). The number of HLA-DR matches was smaller and the number of preoperative transfusions and duration of dialysis were significantly greater for those patients

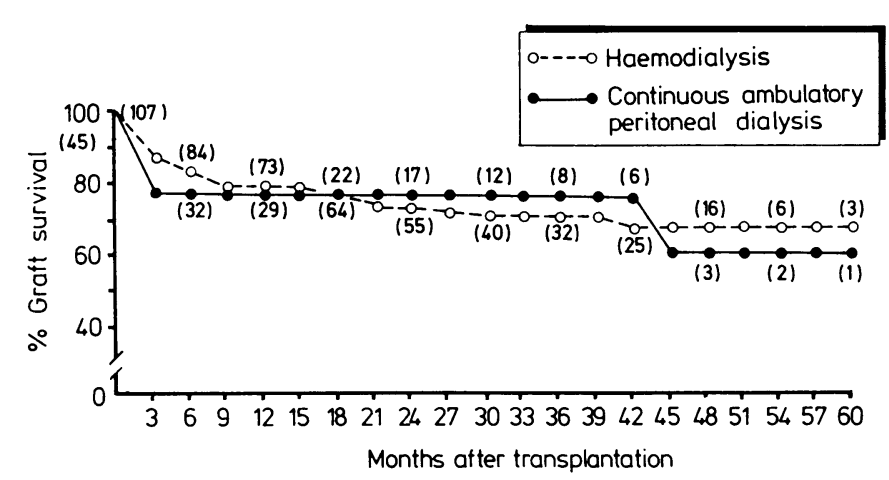

FIG 2-Survival of first cadaver renal allografts in patients treated with continuous ambulatory peritoneal dialysis and haemodialysis (non-immunological failures excluded $(n=152)$. Values in parentheses are numbers of functioning grafts at each time point.

\section{.}


TABLE II-Details of 152 first cadaver transplant recipients treated with haemodialysis or continuous ambulatory peritoneal dialysis before transplantation

\begin{tabular}{|c|c|c|c|}
\hline & \multicolumn{2}{|c|}{ Treatment } & \multirow[b]{2}{*}{ p Value } \\
\hline & $\begin{array}{l}\text { Haemodialysis } \\
\quad(\mathrm{n}=107)\end{array}$ & $\begin{array}{l}\text { Continuous } \\
\text { ambulatory } \\
\text { peritoneal } \\
\text { dialysis } \\
(n=45)\end{array}$ & \\
\hline \multirow{5}{*}{$\begin{array}{l}\text { Mean (SD) age (years) } \\
\text { (range) } \\
\text { Men :women } \\
\text { Mean (SD) matches: } \\
\text { HLA-A } \\
\text { HLA-B } \\
\text { HLA-DR } \\
\text { Median (range) preoperative } \\
\text { transfusions (units) } \\
\text { Median (range) duration of dialysis } \\
\text { (days) }\end{array}$} & $\begin{array}{c}39 \cdot 1(12 \cdot 4) \\
(13-63)\end{array}$ & $\begin{array}{c}38 \cdot 1(14 \cdot 1) \\
(7-64)\end{array}$ & NS \\
\hline & $70: 37$ & $31: 14$ & NS \\
\hline & $\begin{array}{l}0.98(0.62) \\
1.57(0.52) \\
0.61(0.62)\end{array}$ & $\begin{array}{l}0.91(0.74) \\
1.67(0.54) \\
0.87(0.60)\end{array}$ & $\begin{array}{c}\text { NS } \\
\text { NS } \\
<0.05\end{array}$ \\
\hline & $5(1-47)$ & $4(2-23)$ & $<0.002$ \\
\hline & $696(36-3828)$ & $378(44-1133)$ & $<0.001$ \\
\hline
\end{tabular}

treated with haemodialysis (table II) compared with continuous ambulatory peritoneal dialysis. As these differences in the patients background may have been important for graft survival the covariants (age, sex, HLA-A, HLA-B, HLA-DR antigen matches, preoperative transfusions, duration of dialysis, and type of dialysis) were entered into the Cox proportional hazards model to assess their relative importance for graft survival.

After allowing for the effects of the other covariates continuous ambulatory peritoneal dialysis was estimated to give a slightly better rate of graft survival than haemodialysis (fig 3). The improvement, however, was not significant: the relative risk variable ${ }^{13}$ was estimated at 0.67 but had a $95 \%$ confidence interval of $0.31-1 \cdot 48$. Significant factors were duration of dialysis, number of preoperative transfusions, and HLA-B or HLA-DR antigen matches. ${ }^{15}$

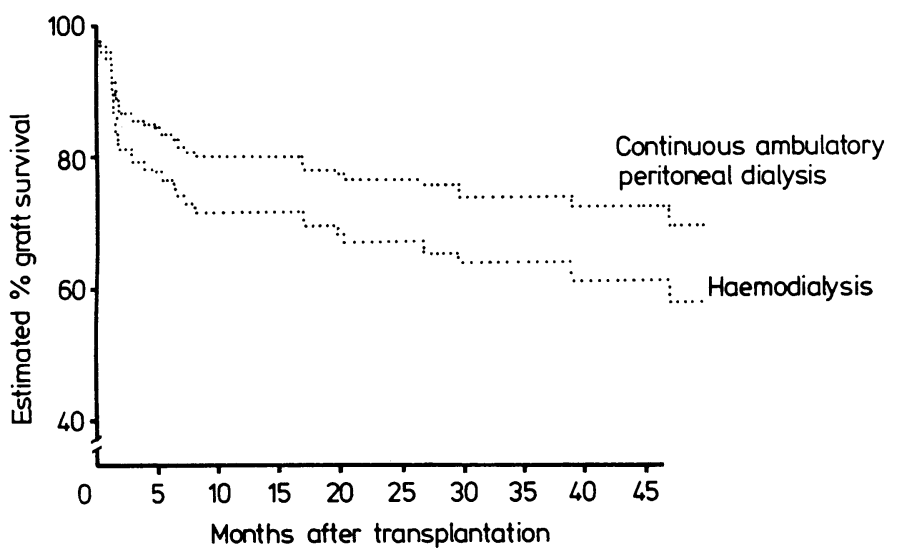

FIG 3-Renal allograft survival in patients treated with continuous ambulatory peritoneal dialysis and haemodialysis before transplantation (Cox proportional hazards model). Estimated \% graft survival for first cadaver re:ipients treated with continuous ambulatory peritoneal dialysis or haemodialysis based on median values of other covariants from all patients studied $(n=152)$ -that is, age (40 years); sex (M); HLA-A matches (one), HLA-B (two), and HLA-DR (one); preoperative transfusions (five); and duration of dialysis (565). Difference in graft survival between continuous ambulatory peritoneal dialysis and haemodialysis recipients not significant.

\section{Discussion}

Since its introduction in 1978 an increasing proportion of the national pool of potential transplant recipients are treated with continuous ambulatory peritoneal dialysis. ${ }^{16}$ Although continuous ambulatory peritoneal dialysis offers considerable advantages over haemodialysis in terms of social independence, general wellbeing, and low capital costs, recurrent peritoneal infection is a problem for some patients. ${ }^{11}$ Paradoxically, patients given continuous ambulatory peritoneal dialysis might be at increased risk of renal allograft rejection because of improved immune competence resulting from better nutrition and reduced requirements for blood transfusions. ${ }^{6}$

Although early successes of renal transplantation may have been due to uraemic immunodepression alone, ${ }^{4}$ its real contribution to survival of grafts in patients receiving regular dialysis is uncertain. Whereas some studies have shown an improvement in immune response with dialysis, ${ }^{17}{ }^{18}$ others have found a progressive deterioration. ${ }^{19}$ Recent reports of differences in in vitro enumeration and function of lymphocyte subsets in patients receiving continuous ambulatory peritoneal dialysis and haemodialysis have been contradictory. ${ }^{6} 182021$

This study confirms an earlier report that excellent survival of allografts can be expected in patients given continuous ambulatory peritoneal dialysis who have received preoperative transfusions and who are treated with azathioprine and prednisolone. ${ }^{22}$ Survival of patients was not significantly different in the two groups, and since introduction of a policy of avoiding transplantation within three weeks of a confirmed episode of peritonitis no deaths have occurred as a result of continuous ambulatory peritoneal dialysis peritonitis in allograft recipients. Although there were slightly more graft failures due to nonimmunological reasons in patients who received continuous ambulatory peritoneal dialysis, the number was not significantly different from those treated with haemodialysis.

Detailed examination of patients' background showed a remarkable similarity in the age and distribution of sex in the two groups, possibly reflecting the policy at this centre of using continuous ambulatory peritoneal dialysis as an effective first line method of treating end stage renal failure. The high proportion of transplants that were HLA-B antigen matched is explained by our deliberate matching policy based on previously shown benefits in recipients who have had transfusions. ${ }^{7}$ The increased proportion of HLA-DR matches among patients who received continuous ambulatory peritoneal dialysis may also reflect a recent policy of accepting HLA-DR matched kidneys that coincided with a greater proportion of potential transplant recipients who had previously received continuous ambulatory peritnneal dialysis.

Continuous ambulatory peritoneal dialysis may reduce requirements for transfusions in renal failure by reducing loss of blood while receiving haemodialysis and more efficient removal of harmful "middle molecules" thought to sustain anaemia.$^{23} \mathrm{~A}$ recent report, however, does not show any difference in the survival of red cells in blood transfused to patients receiving continuous ambulatory peritoneal dialysis or haemodialysis. ${ }^{24}$ In this study although patients treated with continuous ambulatory peritoneal dialysis received significantly fewer transfusions in total than those treated with haemodialysis, the differences may only reflect the relative total duration of dialysis. ${ }^{15}$

Haemodialysis preceded continuous ambulatory peritoneal dialysis as treatment for renal failure, therefore, most patients given transplants from our waiting list had received haemodialysis, and the duration of dialysis exceeded that of those given continuous ambulatory peritoneal dialysis. Recent studies have shown that increased duration of dialysis and number of preoperative blood transfusions improve allograft survival, ${ }^{15}{ }^{25}$ a factor that might favour patients treated with haemodialysis. After allowing for these background variables in the multiple regression model $^{13}$ continuous ambulatory peritoneal dialysis proved to be at least as good as, and possibly superior to, haemodialysis in preparing patients for long term allograft survival.

Continuous ambulatory peritoneal dialysis was first proposed as a method of treating patients who were unsuitable for haemodialysis and was adopted by several centres, predominantly for these so called "high risk" patients. ${ }^{2}$ Inclusion of a high proportion of such patients in an analysis of continuous ambulatory peritoneal dialysis and outcome of transplantation may explain differences from our study, in which continuous ambulatory peritoneal dialysis was, from the outset, used as a first line method of dialysis. Such "centre effect" ${ }^{26}$ differences in the selection and management of renal transplant recipients should be borne in mind when interpreting possible risk factors for graft survival. 
In this study of a homogenous population of transplant recipients who had received transfusions, treated with conventional immunosuppressive drugs, continuous ambulatory peritoneal dialysis was not found to be a risk factor for the survival of patients or grafts, and its continued use in the preparation of patients with end stage renal failure for transplantation is recommended.

We thank the medical and nursing staff of the renal units in the Northern region and Mrs R Grieveson, Mrs E Robson, and Mrs C Hudson for secretarial work.

\section{References}

1 Kolff WJ, Berk HTJ, Welle M, van Ley AJW, van Dijk EC, van Noordwijk J. The artificial kidney : a dialyser with a great area. Acta Med Scand 1944;117:121. Oreopoulos DG, Khanna R, Williams P, Vas SI. Continuous ambulatory peritoneal dialysis-1981. Nephron 1982;30:293-303.

3 Wing AJ, Broyer M, Brunner FP, Brynger $\mathrm{H}$, et al. Combined report on regular dialysis and transplantation in Europe. Proc Eur Dial Transplant Assoc 1983; 20:5-78. 4 Hume DM, Mervill JP, Miller BF, Thorn GW. Experiences with renal trans-

5 Opelz G, Terasaki PI. Dominant effect of transfusion on kidney graft survival.

6 Guillou PJ, Will EJ, Davison AM, Giles GR. CAPD-a risk factor in clinical renal transplantation? Br ₹ Surg 1984;71:878-80

7 Dewar PJ, Wilkinson R, Elliott RW, et al. Superiority of B locus matching over other HLA matching in renal graft survival. $\mathrm{Br}$ Med $\mathcal{f} 1982 ; 284: 779-82$.

8 Dewar PJ, Murray S. Lymphocytotoxic antibody detection and cross matching in renal transplantation. Transplantation 1976;21:387-90.

Striker GE, Tenckhoff AM. A transcutaneous prosthesis for prolonged access to the peritoneal cavity. Surgery 1971;69:70-4. 0 Francis DMA, Donnelly PK, Veitch PS, et al. Surgical aspects of continuous
peritoneal dialysis-3 years' experience. Br $\mathcal{F}$ Surg $1984 ; 71: 225-9$. 11 Ramos JM, Gokal R, Siamopolous $\mathrm{K}$, Ward $\mathrm{MK}$, Wilkinson $\mathrm{R}$, Kerr $\mathrm{DNS}$ ;52:165-86.

12 Lee E, Desu M. A computer program for comparing $\mathrm{K}$ samples with right 3 Cox DR. Regression models and life tables. Ұournal of the Royal Statistical Society, Series B 1972;34:187-220.

14 Sanfilippo F, Vaughn WK, Specs EK, Light JA, le For WM. Benefits of HLA-A and HLA-B matching on graft survival and patient outcome after cadavericdonor renal transplantation. $N$ Engl f Med 1984;311:358-64.

15 Donnelly PK, Henderson R, Lennard TWJ, Proud G, Taylor RMR. Specific and non-specific immunoregulatory factors and renal allograft survivalsingle centre 5 year experience. Transplant Proc (in press).

End demands. Health Trends 1984;16:1-3.

, Hosking CS, Atkins RC. The effect of mainten ance haemodialysis on lymphocyte function I: haemodialysis. Clin Exp Immunol 1978;33:95-101.

18 Collart F, Tielemans C, Dratwa M, Schandene L, Wybran J, Dupont E. Haemodialysis, continuous ambulatory peritoneal dialysis and cellular immunity. Proc Eur Dial Transplant Assoc 1983;20:190-

19 Valderradano F, Anaya F, Perez-Garcia R, Olivas E, Vasconez F, Jofre R. Transfusion-induced anergy: skin test as an index for pretransplant transfusions. $1983 ; 20: 338-48$.

20 Langhoff $E$, Ladefoged J. Improved lymphocyte transformation in vitro of patients on continuous ambulatory peritoneal dialysis. Proc Eur Dial Transplan Assoc $1983 \cdot 20 \cdot 230-5$.

21 Giagrande A, Canta P, Limido A, de Francero D, Malacrida T. Continuous ambulatory peritoneal dialysis and cellular immunity. Proc Eur Dial Transplant Assoc 1982;19:372-9.

22 Gokal R, Ramos JM, Veitch PS, et al. Renal transplantation in patients on continuous ambulatory peritoneal dialysis. Proc Eur Dial Transplant Assoc

$1981 ; 18: 222-7$.
23 Leblr HW, Spiegelhalter R, Ulm A, Goubeaud G, Rawer P. Influence of middle molecules on the anemia of uremic patients. Artif Organs 1978;2:378-81.

24 Salahudeen AK, Hawkins T, Keavey PM, Wilkinson R. Is anaemia during continuous ambulatory peritoneal dialysis better than during haemodialysis

25 Opelz G, Micking rect 1981 XIII :136-41.

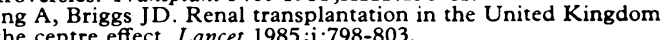
Tancet $1985 ; \mathrm{i}: 798-803$.

(Accepted 10 fuly 1985)

\title{
Renal transplantation in patients treated with haemodialysis and short term and long term continuous ambulatory peritoneal dialysis
}

\author{
JOAO B EVANGELISTA JR, DAVID BENNETT-JONES, J STEWART CAMERON, CHISHOLM OGG, \\ D GWYN WILLIAMS, DAVID H TAUBE, GUY NEILD, CHRIS RUDGE
}

\begin{abstract}
Forty two adult patients who had been treated with continuous ambulatory peritoneal dialysis for one to 142 weeks (mean (SD) 38 (36)) received a total of 44 allografted kidneys. Twenty one had been treated with continuous ambulatory peritoneal dialysis for less than 26 weeks (mean $11(8)$ ) and the other 21 for longer than 26 weeks (mean $64(35)$ ). These two groups were compared with 55 patients who had been treated with haemodialysis and received a total of 63 grafts.

In the group of patients treated with continuous ambulatory peritoneal dialysis azathioprine and low dose prednisolone were used as the immunosuppressive regimen for 20 transplantations in 18 patients, and 24 patients receiving 24 grafts were treated with cyclosporin
\end{abstract}

Renal Unit, Guy's Hospital, London SE1 9RT JOAO B EVANGELISTA Jr, MD, clinical fellow DAVID BENNETT-JONES, BA, MRCP, research registrar J STEWART CAMERON, MD, FRCP, professor of renal medicine CHISHOLM OGG, MD, FRCP, consultant renal physician D GWYN WILLIAMS, MD, FRCP, consultant renal physician DAVID H TAUBE, MB, MRCP, senior registrar GUY NEILD, MB, MRCP, lecturer in medicine CHRIS RUDGE, BSC, FRCS, consultant surgeon

Correspondence to: Dr Ogg.
A and low dose prednisolone. In the group of patients treated with haemodialysis 38 patients receiving 43 grafts were treated with azathioprine and low dose prednisolone, and 20 patients receiving 20 grafts were treated with cyclosporin $A$ and low dose prednisolone.

Actuarial survival of patients and grafts at two years was $95 \%$ and $72 \%$, respectively, in the continuous ambulatory peritoneal dialysis group compared with $89 \%$ and $58 \%$, respectively, in the haemodialysis group. No difference was found in graft survival between short term treatment with continuous ambulatory peritoneal dialysis $(72 \%$ graft survival) and long term treatment $(65 \%$ graft survival).

In conclusion, continuous ambulatory peritoneal dialysis is suitable treatment for patients awaiting renal transplantation.

\section{Introduction}

An increasing number of patients with end stage renal failure throughout the world have been treated with continuous ambulatory peritoneal dialysis since its introduction in 1976. The 1984 report from the European Dialysis and Transplant Association showed that 5228 patients in Europe had been treated with continuous ambulatory peritoneal dialysis up to December 1983. The United Kingdom accounted for almost a third of this total. ${ }^{1}$ The risk of septic complications secondary to the presence of an 